\title{
Quality and Readability of Online Patient Education Information and the Parents Comprehension for Childhood Depression
}

\section{Christia Dickerson, MHIIM ${ }^{1}$, Sajeesh Kumar, PhD $^{2}$}

${ }^{1}$ Research Scholar, Department of Health Informatics \& Information Management, University of Tennessee Health Science Center, Memphis, TN, USA ${ }^{2}$ Associate Professor, Department of Health Informatics \& Information Management, University of Tennessee Health Science Center, Memphis, TN, USA

\begin{abstract}
Depression is a commonly diagnosed mental health illness among people of all ages. Individuals, who have children that battle with depression, or struggle with it themselves, may seek information about depression and treatment options for their diagnosis online. However, there is little research about the quality and reading level of online information for this health condition. The purpose of this study is to evaluate the quality and readability of online patient education information on the topic of depression and parents' comprehension of this information to make sound health decisions for their children who may show signs and symptoms of depression.
\end{abstract}

Keywords: Depression; Mental health; Online patient education

\section{Introduction}

"Individuals have increasingly turned to the Internet for insight into their health questions and concerns" [1]. Since the Web's introduction in the early 1990's, tens of thousands of consumer oriented mental health websites have been created [2]. Over 234 million results come up in the Google search engine when searching the term "mental health," and nearly 200 million results appear in the Google search engine when searching the term "depression." Certainly we view the Internet as an important channel for patient empowerment, enabling patients to feel more knowledgeable and take action to improve their own health. However, this steep volume of information available online can easily become overwhelming, especially for those truly seeking help. The extent to which an individual will benefit from using the Internet as a source of health information depends greatly upon their level of health literacy-one's ability to obtain, process, and understand the basic health information and then apply this information to make sound health decisions.

While "health literacy" is a commonly used term, the subject of mental health literacy is seemingly non-existent. The term "mental health literacy" is defined as "knowledge and beliefs about mental disorders which aid their recognition, management, or prevention." Mental health literacy consists of several components including: "(a) the ability to recognize specific disorders or different types of psychological distress; (b) knowledge and beliefs about risk factors and causes; (c) knowledge and beliefs about self-help interventions; (d) knowledge and beliefs about professional help available; (e) attitudes which facilitate recognition and appropriate help- seeking; and ( $f$ ) knowledge of how to seek mental health information" [3]. Depression is one of the most common mental health disorders that affect nearly 16.1 million Americans [4]. It is a serious illness that can play a crucial role in the way a person acts, feels, and thinks every day, thus affecting how a person comprehends written healthcare material, both printed or online. The purpose of this study is to evaluate the quality and readability of online patient education information for those with depression, as well as parents' comprehension of this information to make sound health decisions for their children who may show signs and symptoms of depression.

\section{Method}

To identify prospective sites to evaluate, the Google search engine was used to locate accessible websites for behavioral health facilities. In this search the key phrase "depression treatment facilities Memphis,
TN" was used to find behavioral health facilities that treated patients with depression. This search returned eight accessible websites that would be the most commonly encountered by the average user. Websites $(n=3)$ were excluded that linked to advertisements for depression, rather than tangible depression treatment facilities. All other sites $(n=5)$ remaining were included in this study (Table 1). Website evaluation criterion was created to evaluate the quality of the five behavioral health facilities (Figure 1).

Microsoft $^{\mathrm{Tx}}$ Word 2011 calculated the readability scores of the depression information listed on the selected behavioral health facilities websites, using both Flesch Reading Ease and Flesch-Kincaid Grade Level tools [5]. "The Flesch Reading Ease test rates text on a 100 -point scale. The higher the score, the easier it is to understand the document. A Flesch readability of $\geq 60$ is considered to be easy to follow. The Flesch-Kincaid Grade Level rates text on a US school grade level. For example, a score 8.0 means someone form the eighth grade can understand the document. The lower score, the easier it is to understand the document" [6]. The Flesch Readability Ease and FleschKincaid Grade Level use a specific mathematical formula to calculate the score and reading age (Figure 2).

This study was conducted at Greater Lewis Street Missionary Baptist Church in Memphis, TN. The church has over 200 members from different ethnic backgrounds. All members of this church were eligible to participate in this study. Participants were excluded if they were under the age of 30 and did not have children aged 17 or younger.

A consent form was provided to each participant along with the survey over a two week period. The paper survey was anonymous and no personal information was collected. The Institutional Review Board approved the consent form and the survey. A total of a 100 participants were provided with the survey; however, per the consent form, if they wished not to participate in the survey, they were free to discard it.

*Corresponding author: Sajeesh Kumar, Department of Health Informatics and Information management, UT Health Science Center, 920 Madison Avenue, suite 518, Memphis, Tennessee, USA, Tel: 901-448-2125; E-mail: skumar10@uthsc.edu

Received December 08, 2015; Accepted January 15, 2016; Published January 20, 2016

Citation: Dickerson C, Kumar S (2016) Quality and Readability of Online Patient Education Information and the Parents Comprehension for Childhood Depression. J Health Med Informat 7: 214. doi:10.4172/2157-7420.1000214

Copyright: (c) 2016 Dickerson C, et al. This is an open-access article distributed under the terms of the Creative Commons Attribution License, which permits unrestricted use, distribution, and reproduction in any medium, provided the original author and source are credited. 


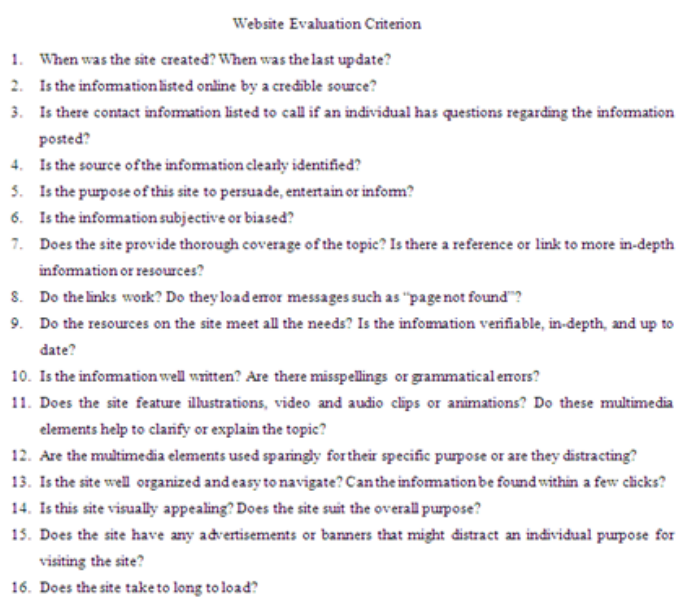

Figure 1: Website evaluation criterion.

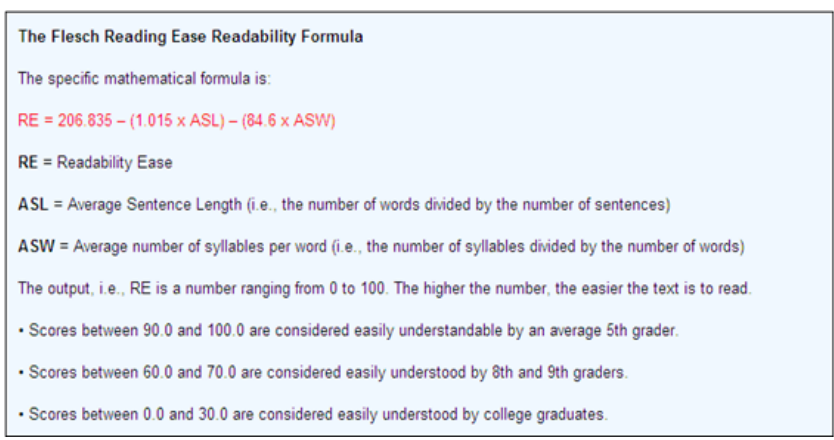

Figure 2: The Flesch Reading Ease Readability Formula (from http://www. readabilityformulas.com/flesch-reading-ease-readability-formula.php).

The content of the questions selected were based on demographics, knowledge about health literacy and depression screening.

\section{Results}

In total five websites were evaluated. Based on the website evaluation criteria, they all offered a thorough overview of depression providing facts, common signs and symptoms, and various treatment options. Contact information was readily available for those seeking help. However, majority did not offer additional features such as external links for more information, videos, or illustrations. On the other hand, The Smith Psych Solutions Clinic was the only facility that offered a self-assessment for individuals to assess whether he or she has or are at risk of having depression. Additionally, this site provided three videos, but only one video worked properly, the other two could no longer be found. The Depression Treatment Center and RehabDelta Medical Center website was too busy. There was information that did not pertain to depression that would distract one from getting the information they need. Likewise, Mental Health Resources, PLLC site has not been updated since 2013. Overall, each website fulfilled its intended purpose, was well organized, and easy to navigate.

After evaluating the quality of each site, the information found was assessed to present readability statistics. The Flesch Reading Ease scores of the websites evaluated ranged from 20.6 to 36.5, with a median score of 15.9. Flesch-Kincaid Grade Levels were dissimilar. As shown in the chart (Figure 3) below, all sites scored a Flesch-Kincaid Grade Level of
12.With the use of the Flesch-Kincaid statistical tool; it revealed that these five behavioral health websites are written at or above college grade level. Individuals, who are not educated at the college level and have poor health literacy, may have difficulty comprehending this information to make basic health decisions.

Of the 100 participants, 24 declined to participate and the remaining 76 agreed to proceed with taking the survey totaling to $76 \%$ participation. This survey aimed to identify parents who were not previously familiar with health literacy, to determine if they were able to recognize depression symptoms in both their children and themselves. The survey captured the key characteristics of the population, shown in Table 2 below.

Survey also focused on parents' awareness of health literacy, their experience with depression, their ability to recognize depression in their children, their ability to comprehend online health information and seek treatment for their children based on they read. The survey revealed that only $80 \%$ of the participants had heard of the term "health literacy". When asked, "If you are ever unclear about your doctor's orders, what method(s) do you use to clarify them?" $80 \%$ stated that they speak to the doctor, while $28 \%$ stated that they search the Internet, as shown in the chart below, Figure 4 . The survey identified children who show signs or symptoms of depression. As shown in Table 3 below, $51 \%$ of the participants admitted that that their child has signs or symptoms of depression, often, $20 \%$ were unable to identify depression symptoms.

At the end of the survey, participants were provided with a sample of online health information from one of the selected websites used in this study. Participants were asked if they had difficulty understanding the information they read, $13 \%$ admitted having difficulty comprehending the information, $3 \%$ did not know, and $6 \%$ was not sure. Additionally, participants were asked if they would be confident in seeking treatment for their child after reading the information provided. $51 \%$ of the participants stated, yes, $14 \%$ said, no, and $24 \%$ admitted in being unsure. Lastly, participants were asked if the online information could be written better. $22 \%$ of the participants stated, yes.

The results of this survey revealed that there are parents who are knowledgeable of health literacy but are unfamiliar with its meaning. Moreover, there are parents who have difficulty comprehending online health information and trusting the information available to make sound health decisions for their children.

\section{Discussion}

An individual with adequate health literacy has the mental capacity, knowledge, and confidence to navigate the healthcare system, seek proper care, and make informed health care decisions. On the other hand, patients with inadequate health literacy encounter numerous challenges when accessing and exploring options in the health care system. Literacy problems can hinder a patient's ability to comprehend doctor's orders, follow prescription directions, or complete forms because he or she is ashamed to ask for help [7]. Research evidence concludes that poor health literacy is directly associated with one's health status as well as a person's mental health. However, poor health literacy is not an independent predictor of clinical major depression [8].

Depression is a serious illness that plagues society. It transcends across all cultural boundaries, race, religion, and creed. Although depression is a common mental health disorder, many wrongly disregard it because of one's knowledge and beliefs about depression 
Citation: Dickerson C, Kumar S (2016) Quality and Readability of Online Patient Education Information and the Parents Comprehension for Childhood Depression. J Health Med Informat 7: 214. doi:10.4172/2157-7420.1000214

Page 3 of 5

BEHAVIORAL HEALTH FACITILIES IN THE MEMPHIS, TN AREA

Depressions Treatment Center and Rehab-Delta Medical Center

Lakeside Behavioral Health

Memphis TMS

Mental Health Resources, PLLC

The Smith Psychsolutions Clinic

Table 1: Selected behavioral health facilities.

\begin{tabular}{|c|c|c|c|c|c|}
\hline \multicolumn{6}{|c|}{ Characteristics of study participants $(n=76)$} \\
\hline Gender & $\mathrm{n}$ & $(\%)$ & Annual Household Income & $\mathrm{n}$ & $(\%)$ \\
\hline Male & 20 & $(26)$ & $\$ 0-\$ 9,999$ & 4 & $(5)$ \\
\hline Female & 56 & $(74)$ & $\begin{array}{l}\$ 10,000-\$ 19,999 \\
\$ 20,000-\$ 29,999\end{array}$ & $\begin{array}{l}11 \\
7\end{array}$ & $\begin{array}{c}(14) \\
(9)\end{array}$ \\
\hline Ethinicity & & & $\$ 30,000-\$ 39,999$ & 10 & (13) \\
\hline Caucasian & 9 & $(12)$ & $\$ 40,000-\$ 49,999$ & 16 & $(21)$ \\
\hline African-American & 64 & $(84)$ & $\$ 50,000$-or more & 20 & $(26)$ \\
\hline Hispanic & 2 & (3) & Rather not say & 8 & (11) \\
\hline Other & 1 & (1) & & & \\
\hline \multicolumn{6}{|c|}{ Marital Status } \\
\hline Age, Years & & & Single, never married & 21 & (28) \\
\hline $30-40$ & 39 & $(51)$ & $\begin{array}{l}\text { Married or Domestic } \\
\text { partnership }\end{array}$ & 37 & (49) \\
\hline $41-50$ & 24 & (32) & Widowed & 3 & (4) \\
\hline Older than 50 & 12 & $(16)$ & $\begin{array}{l}\text { Divorced } \\
\text { Separated }\end{array}$ & $\begin{array}{l}11 \\
4\end{array}$ & $\begin{array}{c}(14) \\
(5)\end{array}$ \\
\hline \multicolumn{6}{|l|}{ Education } \\
\hline Some high school & 8 & (11) & Employment status & & \\
\hline $\begin{array}{c}\text { High school Diploma or } \\
\text { equivalent }\end{array}$ & 16 & $(21)$ & Full time & 59 & (78) \\
\hline $\begin{array}{l}\text { Some college but no } \\
\text { degree }\end{array}$ & 16 & $(21)$ & Part time & 8 & (11) \\
\hline Associates Degree & 8 & (11) & Unemployed & 4 & (5) \\
\hline Bachelor's Degree & 19 & (25) & Retired & 3 & (4) \\
\hline Graduate Degree & 10 & (13) & Disabled & 0 & (0) \\
\hline & & & Student & 0 & $(0)$ \\
\hline & & & Rather not say & 2 & (3) \\
\hline
\end{tabular}

Table 2: Characteristics of study population.

\begin{tabular}{|c|c|c|}
\hline \multicolumn{3}{|c|}{ Depression Screening Questions } \\
\hline Question & $\mathrm{n}$ & $(\%)$ \\
\hline \multicolumn{3}{|c|}{ Little pleasure or interest in doing things } \\
\hline >Often & 9 & $12 \%$ \\
\hline$>$ I am not sure & 1 & $1 \%$ \\
\hline \multicolumn{3}{|c|}{ Trouble falling or staying asleep, sleeping too much } \\
\hline$>$ Often & 9 & $12 \%$ \\
\hline$>$ I am not sure & 5 & $7 \%$ \\
\hline \multicolumn{3}{|c|}{ Poor appetite or eating too much } \\
\hline >Often & 6 & $8 \%$ \\
\hline$>$ I am not sure & 5 & $7 \%$ \\
\hline \multicolumn{3}{|c|}{ Trouble concentrating on things like school work or chores } \\
\hline$>$ Often & 15 & $20 \%$ \\
\hline$>1$ am not sure & 4 & $5 \%$ \\
\hline \multicolumn{3}{|c|}{ Total Responses } \\
\hline$>$ Often & 39 & $51 \%$ \\
\hline$>$ I am not sure & 15 & $20 \%$ \\
\hline
\end{tabular}

Table 3: Depression screening questions. 


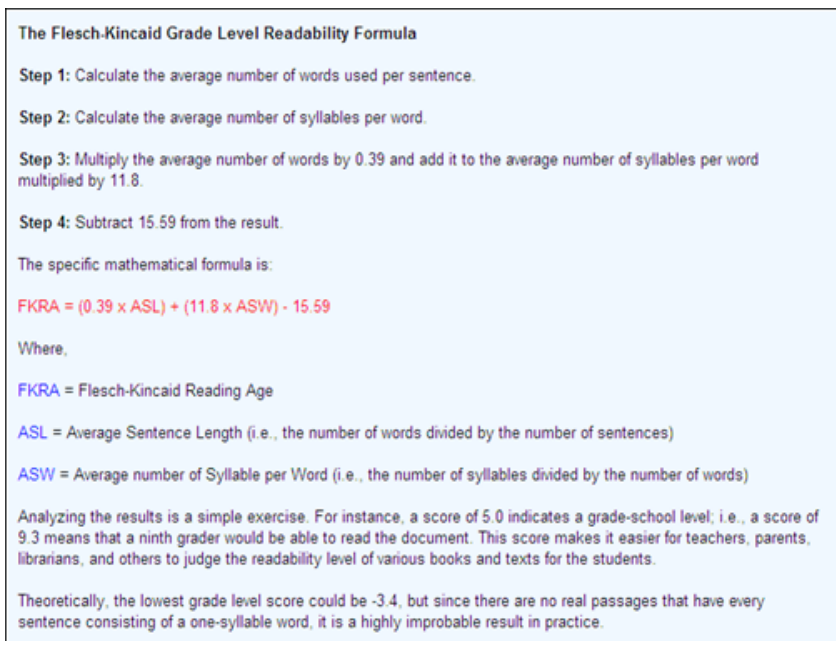

Figure 3: The Flesch-Kincaid Grade Level Readability Formula (from http:// www.readabilityformulas.com/flesch-grade-level-readability-formula.php).

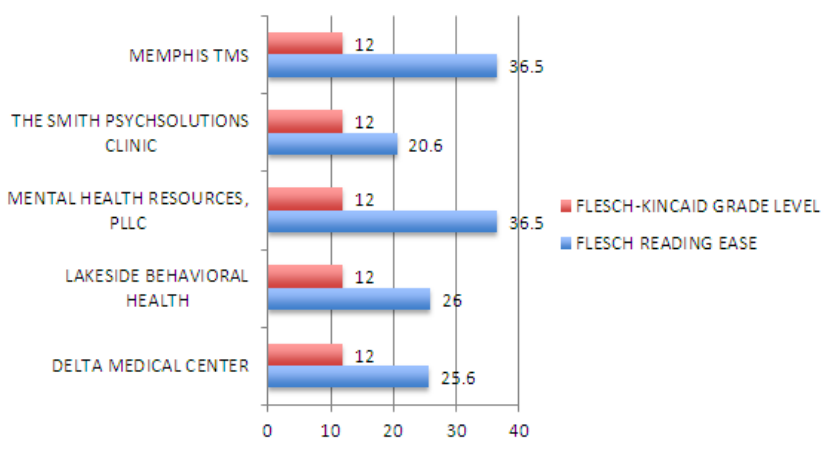

Figure 4: Readability statistics

and acceptance of such diagnosis. In this regard, depression literacy creates a psychological barrier to treatment, such as a lack of knowledge about the illness, as well as minimization of the need for care [9]. Some patients are apprehensive to accept a diagnosis of depression because of the stigma surrounding depression. But those who accept their diagnosis may seek help from various sources, including references, online. While the Internet has proven to be a great source of information for consumers, these studies conclude, "There is a need for better evidence based information on depression on the web" [10]. Distinguishing the good information from the bad proves to be one of the main challenges that face patients with depression. Certainly, there is an abundance of online patient education material for depression. While much of this information appears to be useful, the overall quality of the majority of these sources is poor and the reading level is typically fairly high often graded at a twelfth grade level or higher. These results indicate that patients with poor health literacy skills may delay seeking treatment for their illness, if at all, because the information incomprehensible. Therefore, "If people are relying on the Internet to make treatment decisions, including whether to seek care, deficiencies in information could negatively influence consumer decisions" [11].

This study reveals some significant limitations. First, the initial search strategy did not yield any research articles or peer reviews about mental literacy. This finding signified the limited amount of information about the topic as it relates to depression and health literacy. Second, the study evaluated five local Memphis behavioral healthcare facility websites and cannot provide a general conclusion of all behavioral healthcare facilities in the Memphis, TN area. However, because of the wealth of information available on each site, the results are more likely to reflect the same with other sites. Third, the readability formula in Microsoft Word only has the capability to grade up to a twelfth grade level. It is a possibility that the information assessed could have scored higher than a twelfth grade reading level if other readability statistics tools had been utilized. Fourth, the study population included predominately African-American women. While, depression may affect other races more than others, focusing specifically on one race does not give a generalized view of health literacy as it relates to depression amongst all ethnic backgrounds.

Authors of online health information must be accountable for the information being provided to ensure that it is factual and not speculative, accurate and not imprecise, complete and not partial and balanced and not one sided. This will empower patients who are struggling with the acceptance of their diagnosis of depression to make sound health decisions that will improve their quality of life. Improving health literacy is the responsibility of all health care professionals (HCPs). Communication is a key essential for HCPs when treating patients. They should take their time to assess their patient population to identify patients with inadequate literacy skills [12]. Additionally, the need to establish effective lines of communication should be established so that their patients feel comfortable asking questions about information they may not understand. HCPs should give their responses to such questions in layman's terms rather than medical terminology. Overall, HCPs should be polite, sensitive, and supportive of their patients to encourage them to contribute to their own health care.

\section{Conclusion}

Quality of online health information is crucial to mental health outcomes. Patients who suffer from depression and have poor health literacy have a wealth of information at their fingertips. Current study reports that there are parents who are knowledgeable of health literacy but are unfamiliar with its meaning. Moreover, there are parents who have difficulty comprehending online health information and trusting the information available to make sound health decisions for their children.

\section{References}

1. Jain AV, Bickham DS (2014) Adolescent health literacy and the Internet Challenges and Opportunities. Current Opinions in Pediatrics 26: 435-439.

2. Grohol J (2013) Evaluating the quality of mental health websites.

3. Jorm AF (2000) Mental health literacy: Public knowledge and beliefs about mental disorders. British Journal of Psychiatry 177: 396-401.

4. Depression (2015) Memphis TMS.

5. Flesch-Kincaid Grade Level Readability Formula (2015).

6. Protheroe J, Estacio EV, Saidy KS (2015) Patient information materials in general practices and promotion of health literacy: an observational study of their effectiveness. British Journal of General Practices 65: 192-197.

7. Safeer RS, Keenan J (2005) Health literacy: the gap between physicians and patients. American Academy of Family Physicians 72: 463-468.

8. Wolf MS, Gazmaraian JA, Baker DW (2005) Health literacy and functional health status among older adults. Journal of American Medical Association 105: 1946-1952. 
Citation: Dickerson C, Kumar S (2016) Quality and Readability of Online Patient Education Information and the Parents Comprehension for Childhood Depression. J Health Med Informat 7: 214. doi:10.4172/2157-7420.1000214

Page 5 of 5

9. Gabriel A, Violato C (2010) Depression literacy among patients and the public: A literature review. Primary Psychiatry 17: 55-64.

10. Griffiths KM, Christensen H (2000) Quality of web based information on treatment of depression: cross sectional survey. BMJ 321: 1511.
11. Berland GK, Elliott MN, Morales LS, McGlynn EA (2000) Health Information on the Internet: Accessibility, Quality and Readability in English and Spanish. Journal of American Medical Association 285: 2612-2621.

12. Chew LD, Bradley KA, Boyko EJ (2004) Brief questions to identify patients with inadequate health literacy. Family Medicine 36: 588-594. 